\title{
Semiquantitative Multielemental Analysis of Biological Samples by a Laser Ionization Orthogonal Time-of-Flight Mass Spectrometer
}

\author{
Lizhi Chen, ${ }^{\mathrm{a}}$ Lin Lin, ${ }^{\mathrm{a}}$ Quan Yu, ${ }^{\mathrm{a}}$ Xiaomei Yan, ${ }^{\mathrm{a}}$ Wei Hang, ${ }^{\mathrm{a}, \mathrm{b}}$ Jian He, ${ }^{\mathrm{c}}$ \\ and Benli Huang ${ }^{\mathrm{a}}$ \\ ${ }^{a}$ Key Laboratory for Chemical Biology of Fujian Province, College of Chemistry and Chemical Engineering, \\ Xiamen University, Xiamen, China \\ ${ }^{\mathrm{b}}$ State Key Laboratory of Marine Environmental Science, Xiamen University, Xiamen, China \\ ${ }^{c}$ Department of Mechanical and Electrical Engineering, Xiamen University, Xiamen, China
}

\begin{abstract}
Semiquantitative multielemental analyses of biological samples (tea leaf standard, Laminaria japonica, and pig skin) were demonstrated with a newly developed laser ionization orthogonal time-of-flight mass spectrometer (LI-O-TOFMS). The sample was directly ablated and ionized with high irradiance after simple sample preparation. Relative sensitivity coefficients (RSC) were calculated and evaluated for sensitivity differences. Due to the employment of a collisional cooling device and the orthogonal geometry of the TOF system, high resolving power can be obtained, such that elemental peaks and interferential peaks with the same nominal mass can be distinguished. The detection limit of $\mu \mathrm{g} \mathrm{g}^{-1}$ levels can be commonly achieved for elemental determination. (J Am Soc Mass Spectrom 2009, 20, 1355-1358) (c) 2009 American Society for Mass Spectrometry
\end{abstract}

$\mathrm{D}$ irect laser-induced analytical techniques, such as laser ablation inductively coupled plasma mass spectrometry (LA-ICP-MS), laser-induced breakdown spectrometry (LIBS), and laser ionization mass spectrometry (LIMS), were reputable for direct solid analysis mainly ascribed to little sample preparation. The LA-ICP-MS has been developed to a mature stage with low detection limits [1, 2]. However, its limitations, such as large consumption of inert gas [3] and some spectral interferences, are still not well solved. The LIBS has showed the capability for elemental analysis with wide applications due to its fast analytical speed [4] and low cost, yet only qualitative results can be obtained for most research $[5,6]$. The LIMS instruments have played an important role for direct solid analysis, especially for biological sample analysis [7, 8]. Molecular information can be obtained at low laser irradiance $\left(10^{5}-10^{8} \mathrm{~W} / \mathrm{cm}^{2}\right)$, while elemental information would be provided at high irradiance $\left(10^{9}-10^{10} \mathrm{~W} / \mathrm{cm}^{2}\right)$ [9]. Nevertheless, if high laser irradiance was chosen, the large kinetic energy distribution of the ions would lead to poor mass resolution, and the spectrum is hardly useful for analytical purpose.

Our LI-O-TOFMS was carried out in the source filled with inert gas at low pressure. It uses high laser irradiance $\left(10^{10} \mathrm{~W} / \mathrm{cm}^{2}\right)$ focusing on the sample surface for ablation and ionization. An ion guide cooling cell

Address reprint requests to Professor W. Hang, Xiamen University, Key Laboratory for Chemical Biology of Fujian Province, College of Chemistry and Chemical Engineering, Xiamen 361005, China. E-mail: weihang@ xmu.edu.cn was used to reduce the kinetic energy distribution of ions. This system has unique advantages, including high resolving power at high laser irradiance and low spectral interferences. Therefore, the LI-O-TOFMS should be suitable for biological analysis. The aim of this work is to study the capability of the system for semiquantitative analysis of trace elements in three types of biological samples (tea leaf standard, Laminaria japonica, and pig skin).

\section{Experimental}

The experiments were carried on with an in-house-built laser ionization orthogonal time-of-flight mass spectrometer, which was developed recently and described in detail in [4]. However, the transmission system was modified. In the previous system, hardly any signals of low mass elements $(m / z<40)$ can be obtained, which is caused by the mass discrimination of the two hexapoles since light ions were excessively cooled in hexapole and could not pass the transmission system. In the current system, a set of electrostatic lenses were mounted to replace the first hexapole. This change alleviates the mass discrimination problem, such that low mass elements can be detected.

The pulverized tea leaf was a standard reference material (GBW10016, Chinese Academy of Sciences). After drying in a dry chamber at $70{ }^{\circ} \mathrm{C}$, the sample was pressed in a homemade die under a pressure of $2 \times 10^{8}$ Pa for $3 \mathrm{~min}$ to produce a disk of $1.5 \mathrm{~mm}$ in thickness and $6 \mathrm{~mm}$ in diameter. 
The Laminaria japonica and pig skin were well washed by deionized water and then dried in a vacuum oven. The samples were cut into small pieces and mounted on the direct insertion probe (DIP). The DIP was mechanically rotated to provide fresh sample surface after 200 laser shots at the same spot. For ICP-MS quantification, small pieces of samples about $0.1 \mathrm{~g}$ were digested in a microwave digestion system. Blanks were prepared following the same procedure without sample added. The preparation of Laminaria japonica for iodine determination followed the procedure in [10]. ICP-MS (Agilent 4500) was used for the elemental quantification of the Laminaria japonica and pig skin. Three replicated measurements were made for each solution.

\section{Results and Discussion}

Similar to other techniques for direct solid sample analysis, RSC was used for correcting different elemental sensitivities in our research. The RSC formulation has been presented in [11]. ${ }^{56} \mathrm{Fe}$ was used as the reference element in all experiments due to its appropriate concentration. In our system, laser irradiance and ion source pressure are the major factors influencing the analytical results [4]. It was found that high laser irradiance was favorable for elemental analysis, while appropriate injection of inert gas into the ion source could reduce spectral interferences effectively. After experiments for parameter optimization, the source pressures and laser irradiances for

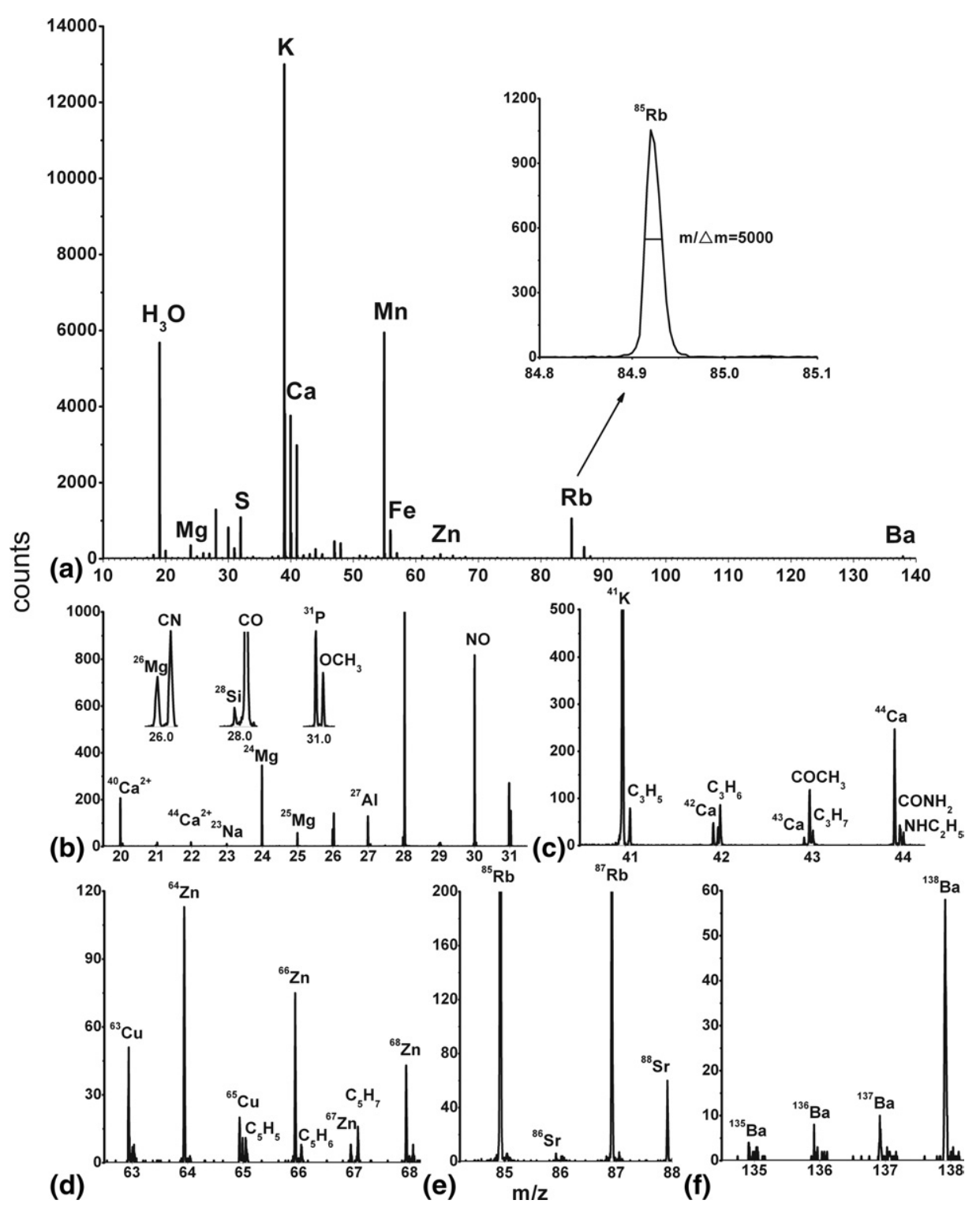

Figure 1. Spectrum of tea leaf standard for $9 \times 10^{4}$ laser shots. (a) The overview of spectrum, with spectrum inserted showing the real peak shape and mass resolution, $(\mathbf{b})-(\mathbf{f})$ are the enlarged regions of the spectrum. 
Table 1. Compositions (in $\mu \mathrm{g} \mathrm{g}^{-1}$ ) and RSCs of tea leaf standard, Laminaria japonica, and pig skin

\begin{tabular}{|c|c|c|c|c|c|c|}
\hline \multirow[b]{2}{*}{ Elements } & \multicolumn{2}{|c|}{ Tea leaf standard } & \multicolumn{2}{|l|}{ Laminaria japonica } & \multicolumn{2}{|l|}{ Pig skin } \\
\hline & Certified conc. & $\mathrm{RSC}$ & Measured conc. by ICP-MS & $\mathrm{RSC}$ & Measured conc. by ICP-MS & $\mathrm{RSC}$ \\
\hline $\mathrm{Na}$ & 90 & 0.02 & 16194 & 0.002 & 1396 & 0.003 \\
\hline $\mathrm{Mg}$ & 1860 & 0.03 & 12477 & 0.002 & 2897 & 0.001 \\
\hline $\mathrm{Al}$ & 940 & 0.02 & 533 & 0.005 & 12 & 0.013 \\
\hline $\mathrm{K}$ & 16300 & 0.40 & 10367 & 0.10 & 471 & 0.10 \\
\hline $\mathrm{Ca}$ & 3260 & 0.44 & 5495 & 0.15 & 66 & 0.11 \\
\hline $\mathrm{Cr}$ & - & - & - & - & 1.5 & 1.90 \\
\hline $\mathrm{Ti}$ & - & - & 9.2 & 2.36 & - & - \\
\hline $\mathrm{Mn}$ & 500 & 2.09 & 32.9 & 0.50 & - & - \\
\hline $\mathrm{Fe}$ & 242 & 1.00 & 179 & 1.00 & 27 & 1.00 \\
\hline $\mathrm{Ni}$ & - & - & - & - & 1.5 & 0.75 \\
\hline $\mathrm{Cu}$ & 18.6 & 1.11 & 16.3 & 0.89 & 3.5 & 0.94 \\
\hline $\mathrm{Zn}$ & 51 & 1.05 & 62.4 & 0.63 & 4.7 & 1.12 \\
\hline As & - & - & 16.3 & 1.30 & - & - \\
\hline $\mathrm{Rb}$ & 117 & 2.59 & 8.6 & 0.97 & 5.2 & 0.76 \\
\hline $\mathrm{Sr}$ & 9.6 & 1.89 & 839 & 2.36 & - & - \\
\hline 1 & - & - & 575 & 2.39 & - & - \\
\hline $\mathrm{Ba}$ & 9.1 & 6.23 & 59.6 & 7.94 & 0.41 & 8.91 \\
\hline $\mathrm{Pb}$ & - & - & - & - & 0.43 & 18.86 \\
\hline
\end{tabular}

different samples were optimized separately because of their different absorptivities.

The spectrum (Figure 1) of tea leaf standard was obtained at the irradiance of $2.6 \times 10^{10} \mathrm{~W} / \mathrm{cm}^{2}$ and source pressure of $530 \mathrm{~Pa}$. The signals of potassium and calcium are saturated due to their high concentrations. Therefore, their less abundant isotopes were chosen for RSC calculation. It can be found that not only the metal elements were presented, but also the nonmetals, such as phosphorus and sulfur, were detected. Moreover, trace isotope peaks, such as ${ }^{86} \mathrm{Sr}\left(0.64 \mu \mathrm{g} \mathrm{g}^{-1}\right),{ }^{135} \mathrm{Ba}(0.63$ $\left.\mu \mathrm{g} \mathrm{g}^{-1}\right),{ }^{136} \mathrm{Ba}\left(0.76 \mu \mathrm{g} \mathrm{g}^{-1}\right)$, and ${ }^{137} \mathrm{Ba}\left(1.12 \mu \mathrm{g} \mathrm{g}^{-1}\right)$ were observed with their isotope ratios matched. For doubly charged ions, only $\mathrm{Ca}^{2+}$ peaks were found, which were mainly caused by high concentration and low second ionization potential $(11.87 \mathrm{eV})$ [12]. The mass resolving power of the spectrum was about 5000. With such a high resolving power, the isotopes and their adjacent peaks of the same nominal mass were able to be distinguished. For example, ${ }^{26} \mathrm{Mg}$ and its adjacent peak, which was considered as $\mathrm{CN}$ were separated. All the organic ions identified were recognized via their accurate masses.

Table 1 lists the RSCs of different metal elements. It can be observed that the RSCs of $\mathrm{Na}, \mathrm{Mg}$, and $\mathrm{Al}$ were less than 0.1. Such low RSCs were mainly caused by the mass discrimination of the cooling cell during ion transmission process. Light ions would lose more energy than heavy ions by collisions with buffer gas. Thus, only a few light ions could pass through the cooling cell to be detected. The same reason applies to light matrix elements of $\mathrm{C}, \mathrm{N}, \mathrm{H}$, and $\mathrm{O}$ that were barely observed. The RSCs of other elements were in the range of 0.6-7.0, which agrees with the semiquantitative analysis criteria $[9,13]$.

The uncertified samples of Laminaria japonica and pig skin were digested and analyzed by ICP-MS as illus- trated previously. The results were given in Table 1. As for LI-O-TOFMS analysis, different irradiances and source pressures were utilized due to the absorptivity differences of various samples. The laser irradiances for Laminaria japonica and pig skin were $1.8 \times 10^{10} \mathrm{~W} / \mathrm{cm}^{2}$ and $1.0 \times 10^{10} \mathrm{~W} / \mathrm{cm}^{2}$, while the ion source pressures were set at 360 and $400 \mathrm{~Pa}$, respectively. Their mass spectra are shown in Figures 2 and 3.

Other than metal elements, Laminaria japonica contains several particular nonmetals, such as strontium and iodine, which were observed in Figure 2. Compared with the spectrum of tea leaf similar categories of elements can be found, though great discrepancies of elemental concentrations exist between the two samples. The peaks of elements and their isotopes were distinct; and the ratios of the isotopes were reasonable. In Figure 2, the mass peak of arsenic was detected, which was dispersed commonly in marine algae samples [14, 15]. Like the tea sample, the RSCs of light ions listed in Table 1 are relatively low, and others were acceptable for semiquantitative analysis.

Pig skin contains some light metal elements including $\mathrm{Na}, \mathrm{Mg}, \mathrm{K}$, and $\mathrm{Ca}$, which showed small sensitivity

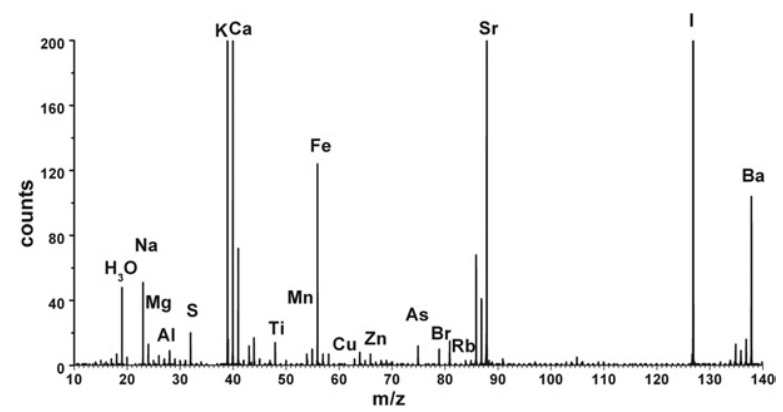

Figure 2. Mass spectrum of Laminaria japonica for $1.8 \times 10^{4}$ laser shots. 


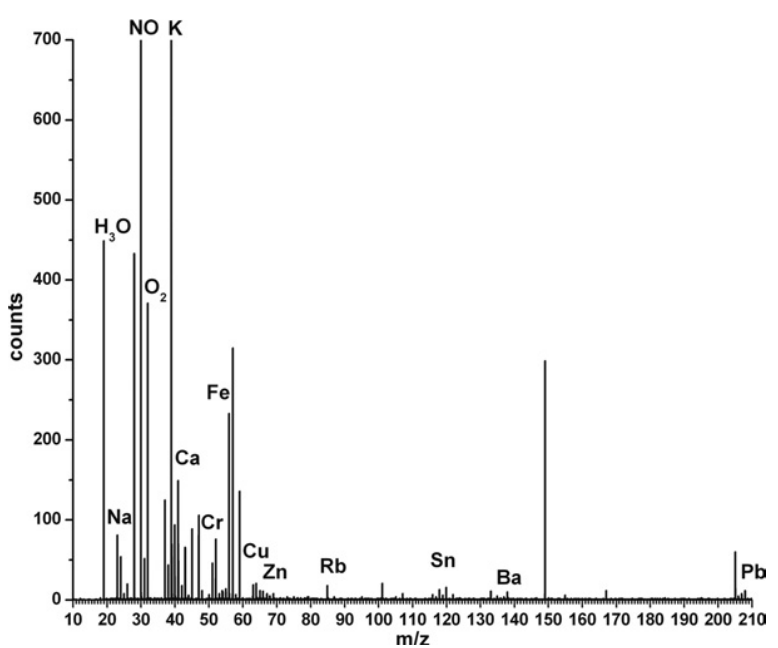

Figure 3. Mass spectrum of pig skin for about $1.8 \times 10^{4}$ laser shots.

due to the system limitation (Figure 3 and Table 1). Besides, it contains considerable trace elements such as $\mathrm{Fe}, \mathrm{Cu}, \mathrm{Zn}, \mathrm{Rb}$, etc. The appearance of $\mathrm{Sn}$ and $\mathrm{Pb}$, which were identified both in ICP-MS and LI-O-TOFMS according to their isotope patterns, could most likely attributed to environmental contamination. The signals of $\mathrm{NO}^{+}$and $\mathrm{O}_{2}{ }^{+}$may be caused by the relatively low laser irradiance [16]. The high sensitivity of $\mathrm{Pb}$ could be caused by its low melting point and thermal effect in the ablation process. There are some polyatomic peaks in mass spectrum, such as 57, 149, and $205 \mathrm{u}$, which were considered as organic fragments. Fortunately, they do not overlap elemental peaks for identification and quantitation.

Among the three biological samples analyzed, similar trace elements were found, such as $\mathrm{Na}, \mathrm{Mg}, \mathrm{Al}, \mathrm{K}$, $\mathrm{Ca}, \mathrm{Fe}, \mathrm{Cu}, \mathrm{Zn}, \mathrm{Rb}$, and Ba. Sample-specific elements, such as As and I in Laminaria japonica and $\mathrm{Sn}$ and $\mathrm{Pb}$ in pig skin, are related to cell-specific intake, accumulation, excretion, and growing environment. Because of the different light absorptions of the samples, RSCs of the same element in different samples are not constant. Another important characteristic worth mentioning is that unlike enlarged spectrum of tea leaf in Figure 1, spectra of Laminaria japonica and pig skin have much less interference. This could be attributed to the difference between the loose structure of pulverized tea sample and directly dried Laminaria japonica and pig skin samples. Except for the low sensitivity of light elements due to the instrumental limitation, RSCs of elements are in a reasonable range that can be used for semiquantitative analysis.

\section{Conclusions}

This work has illustrated the capability for direct elemental analysis of biological samples by our homemade
LI-O-TOFMS. All metal elements with concentration above $\mu \mathrm{g} \mathrm{g}^{-1}$ levels in the sample can be detected with the help of low-pressure ion source and ion guide cooling cell. High resolving power was achieved so that peaks of elements and their adjacent interferences of the same nominal mass could be distinguished. The RSCs of most elements were acceptable for semiquantitative analysis. Sensitivities for light elements were relatively low due to the mass discrimination of cool cell, where efforts will be made in our future work.

\section{Acknowledgments}

The authors acknowledge support for this work by Fujian Province Department of Science and Technology, National Natural Science Foundation of China, and National 863 program.

\section{References}

1. Denoyer, E. R. Semiquantitative Analysis of Environmental Materials by Laser Sampling Inductively Coupled Plasma Mass Spectrometry. J. Anal. At. Spectrom. 1992, 7, 1187-1193.

2. Narewski, U.; Werner, G.; Schulz, H.; Vogt, C. Application of Laser Ablation Inductively Coupled Mass Spectrometry (LA-ICP-MS) for the Determination of Major, Minor, and Trace Elements in Bark Samples. Fresenius J. Anal. Chem. 2000, 366, 167-170.

3. Durrant, S. F. Laser Ablation Inductively Coupled Plasma Mass Spectrometry: Achievements, Problems, Prospects. J. Anal. At. Spectrom. 1999, 14, 1385-1403.

4. Peng, D.; He, J.; Yu, Q.; Chen, L. Z.; Hang, W.; Huang, B. L. Parametric Evaluation of Laser Ablation and Ionization Time-of-Flight Mass Spectrometry with Ion Guide Cooling Cell. Spectrochim. Acta B 2008, 63, $868-874$.

5. Samek, O.; Lambert, J.; Hergenröder, R.; Liška, M.; Kaiser, J.; Novotný, K.; Kukhlevsky, S. Femtosecond Laser Spectrochemical Analysis of Plant Samples. Laser Phys. Lett. 2006, 3, 21-25.

6. Kaiser, J.; Samek, O.; Reale, L.; Liška, M.; Malina, R.; Ritucci, A.; Poma A.; Tucci, A.; Flora, F.; Lai, A.; Mancini, L.; Tromba, G.; Zanini, F.; Faenov, A.; Pikuz, T.; Cinque, G. Monitoring of the Heavy-Metal Hyperaccumulation in Vegetal Tissues by X-Ray Radiography and by Femto-Second Laser Induced Breakdown Spectroscopy. Microsc. Res. Tech. 2007, 70, 147-153.

7. Seydel, U.; Lindner, B. Application of the Laser Microprobe Mass Analyzer (LAMMA) to Qualitative and Quantitative Single Cell Analysis. Int. J. Quantum. Chem. 1981, 20, 505-512.

8. Bakker, A.; Vaeck, L. V.; Jacob, W. Applications of Laser Microprobe Mass Spectrometry in Biology and Medicine. Scanning Microsc. 1996, 10, 753-775.

9. Phipps, C. R.; Dreyfus, R. W. The High Laser Irradiance Regime. In Laser Ionization Mass Analysis, Vertes, A.; Gijbels, R.; Adams, F.; Eds.; Wiley Interscience: New York, 1993; p. 369-385.

10. Larsen, E. H.; Ludwigsen, M. B. Determination of Iodine in Food-Related Certified Reference Materials Using Wet Ashing and Detection by Inductively Coupled Plasma Mass Spectrometry. J. Anal. At. Spectrom. $1997,12,435-439$.

11. Hang, W. Laser Ionization Time-of-Flight Mass Spectrometer with an Ion Guide Collision Cell for Elemental Analysis of Solids. J. Anal. At. Spectrom. 2005, 20, 301-307.

12. Dean, J. A. Lange's Handbook of Chemistry, 12th ed.; McGraw-Hill Education: New York, 1978; p. 3-7.

13. Seltzer, M. D.; Berry, K. H. Laser Ablation ICP-MS Profiling and Semiquantitative Determination of Trace Element Concentrations in Desert Tortoise Shells: Documenting the Uptake of Elemental Toxicants. Sci. Total Environ. 2005, 339, 253-265.

14. Hulle, M. V.; Zhang, C.; Zhang, X. R.; Cornelis, R. Arsenic Speciation in Chinese Seaweeds Using HPLC-ICP-MS and HPLC-ES-MS. Analyst 2002, 127, 634-640.

15. Raber, G.; Francesconi, K. A.; Irgolic, K. J.; Goessler, W. Determination of 'Arsenosugars' in Algae with Anion-Exchange Chromatography and an Inductively Coupled Plasma Mass Spectrometer as Element-Specific Detector. Fresenius J. Anal. Chem. 2000, 367, 181-188.

16. Tanner, S. D. Characterization of Ionization and Matrix Suppression in Inductively Coupled 'Cold' Plasma Mass Spectrometry. J. Anal. At. Spectrom. 1995, 10, 905-920. 